\title{
THE INFLUENCE OF INDUSTRY 4.0 ON THE ENTERPRISE COMPETITIVENESS
}

Date of submission of the article to the Editor: 05/2018

Date of acceptance of the article by the Editor: 07/2018

MAPE 2018, volume 1, issue 1, pp. 641-648

Eng. Renata Stasiak-Betlejewska, PhD.

Czestochowa University of Technology, Poland

\author{
Assoc. Prof. Luminita Parv, PhD. \\ Transilvania University of Braşov, Romania \\ MSc., Eng. Wojciech Gliń \\ Czestochowa University of Technology, Poland
}

\begin{abstract}
Contemporary enterprises are focused on the following dynamic economic, social and technical changes on the market having a big influence on the consumers and producers. Enterprises development is linked with continuous improvement of the entire organization what result in the shaping production organization. Paper presents research results on the effects of an Industry 4.0 implementing within creating Polish enterprise competiveness.
\end{abstract}

Keywords: production, organization, intelligent manufacturing, industry 4.0

\section{INTRODUCTION}

Industry 4.0, defined as the next generation of the industry provides increased flexibility in the manufacturing, along with mass customization, better quality, and improved productivity (Ulewicz and Novy, 2017). It thus enables companies to cope with the challenges of producing increasingly individualized products with a short lead-time to market and higher quality (Ulewicz et al., 2016). Intelligent manufacturing plays an important role in Industry 4.0. Industry 4.0, is defined as a German strategic initiative and it is aimed at creating intelligent factories where manufacturing technologies are upgraded and transformed by cyber-physical systems (CPSs), the Internet of Things (IoT), and cloud computing (Zhong et. al., 2017; Lasi, et al., 2014).

Recent advances in manufacturing industry has paved way for a systematical deployment of Cyber-Physical Systems, within which information from all related perspectives is closely monitored and synchronized between the physical factory floor and the cyber computational space. Moreover, by utilizing advanced information analytics, networked machines will be able to perform more efficiently, collaboratively and resiliently. Such trend transforms the manufacturing industry to the next generation, namely Industry 4.0 (Lee et al., 2015; Wang, et. al., 2016). In the Industry 4.0 era, manufacturing systems are able to monitor physical processes, create a so-called "digital twin" (or "cyber twin") of the physical world, and make smart decisions through real-time communication and cooperation with humans, machines, sensors, and so forth (Wang et. al., 2016).

The industry in the majority of advanced industrially countries in major international companies in the European Union, United States, Japan, and China is affected by the production organization development aimed at fourth stage of industrialization called Industry 4.0. It has started in the early 1970 s what was based on the on electronics and information technologies for realizing a high level of automation in manufacturing what has presently substantial influence on the manufacturing industry. The idea of Industry 4.0 is connected with smart 
factories, smart products and smart services embedded in an internet of things and of services also called industrial internet (Kagermann et al., 2015, Platform Industrie 4.0, 2015).

In Germany the Industry 4.0 strategy was implemented with the great attention to the advances in manufacturing system technology in 2013 (Kagermann, 2013). American initiative on the Advanced Manufacturing Partnership (AMP) was launched in 2011 including other initiatives such as: the Advanced Manufacturing Partnership Steering Committee "2.0" in 2013, the National Network for Manufacturing Innovation (NNMI) in 2014 and the Revitalize American Manufacturing and Innovation Act, which was signed into law by the President of the United States in December 2014 (Revitalize American Manufacturing and Innovation Act, 2014). Chinese initiative was officially published as a 10-year plan and roadmap toward manufacturing in 2015 as Made in China 2025 (Lee, 2015). The largest international collaborative program, Intelligent Manufacturing Systems (IMS), which is led by Japan, is also rolling out a roadmap for its next step with its IMS2020 project. The progress and characteristics of industrial revolutions is presented in Figure 1.

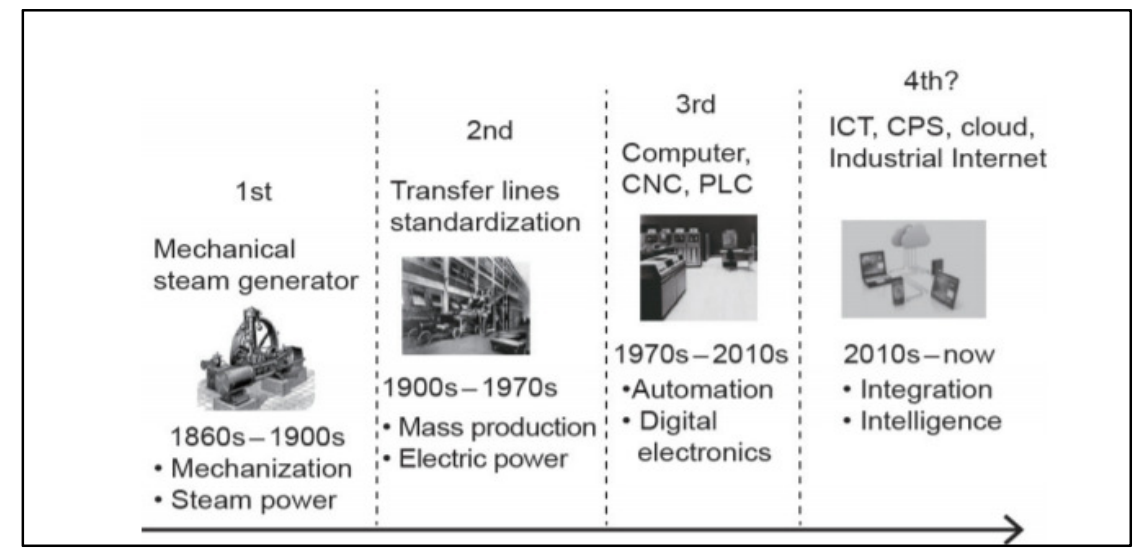

Fig. 1. The progress and characteristics of industrial revolutions. CNC: computer numerical controller; PLC: programmable logic controller; ICT: information and communications technology; CPS: cyber-physical system

In accordance to Yubao Chen (2017), a new manufacturing paradigm is emerging that can be characterized by two unique features: integrated manufacturing and intelligent manufacturing. In the context of Industry 4.0 there are manufacturing systems defined as intelligent manufacturing that requires certain underpinning technologies in order to enable devices or machines to vary their behaviors in response to different situations and requirements based on past experiences and learning capacities (McFarlane, 2003). Similar concepts to intelligent manufacturing include cloud manufacturing. Intelligent manufacturing (also known as smart manufacturing) is a broad concept of manufacturing with the purpose of optimizing production and product transactions by making full use of advanced information and manufacturing technologies (Kusiak, 1990). Industrial practices and implementations consist of the following elements: cybersecurity, advanced materials, 3D printing, predictive analytics, and collaborative robots (Schmidt, 2016).

The aim of the paper is presentation of the art review of an Industry 4.0 and research results on the Industry 4.0 implementing in Polish enterprises production organization.

\section{RESEARCH RESULTS AND DISCUSSION}

Industry 4.0, defined as the next generation of the industry provides manufacturing flexibility with regard to customers and other producers requirements. It is aimed at integrating people and digitally controlled machines to the Internet and information technologies. The materials produced or used during production can always be identified, they also have the ability to 
independently communicate with each other. The flow of information is carried out in two directions:

- vertical - from individual components to the IT department of the company and from the IT department to components,

- level - between machines involved in the production process and the company's production system.

The term Industry 4.0 means therefore the unification of the real world of production machines with the virtual world. Within this, people, machines and IT systems automatically exchange information in the course of production within the factory and various IT systems operating in the enterprise. Industry 4.0 covers the entire value chain from the time of order and delivery of components for the ongoing production until the shipment of goods to customers and aftersales service.

Klaus Schwab, founder of the World Economic Forum in Davos, in the book "The Fourth Industrial Revolution" published in February 2016, gives a clear example of how changes affect the economy (ASTOR, 2016). The three leading Detroit companies, which are the center of traditional industry in 1990, achieved a market capitalization of USD 36 billion and revenues of USD 250 billion. Similarly, three companies from the Silicon Valley in 2014 generated 1.09 trillion USD of capitalization and 247 billion USD of revenues with 10 times less employment. One good news concerning the fourth revolution is that we do not have to wonder whether or not touch us, but how and when it happens. Owing to Industry 4.0, the company may gain additional revenues resulting from:

- digitization of the current portfolio,

- new digital solutions for products and services,

- individual products as well as mass products,

- high margins achieved by larger to-use products to the customers' needs,

- increasing market share within the basic offer.

The enterprise, that introduced Industry 4.0, can expect lower costs and increased efficiency due to:

- quality control in real time,

- modular, flexible and adapted to the recipient's production concept,

- production planning in real time,

- integration of vertical sensors through MES systems,

- horizontal integration, and track and trace system to control product flow.

According to Astor's report in 2016 (Astor Whitepaper, 2016.), the level of automation of Polish production enterprise shows that for the management staff of Polish enterprises to a large extent remain the challenges of the third industrial revolution on microelectronic technology. In the fourth era of the industrial revolution, Polish companies in $76 \%$ are partially automated, fully automated $15 \%$ and enterprises that introduced Industry 4.0 are only $6 \%$.

In contrast, the Siemens report entitled "Smart Industry Poland 2018" shows that as many as $60 \%$ of entrepreneurs have not heard about the concept of Industry 4.0 , and only $15.5 \%$ have considered them in their strategy. In $90 \%$ of enterprises, their owners largely decide to implement new technological solutions. The most important barrier which limit the adaptation of such technology concerning the absence of the center support to such activities (almost $65 \%$ of the responses) and the next barrier is the lack of time (62\%). The barrier, which prevents the advanced industry solution introduction is a lack of qualified staff (53\%). Figure 2 presents data on the industrial revolution level characteristic for Polish enterprises. 


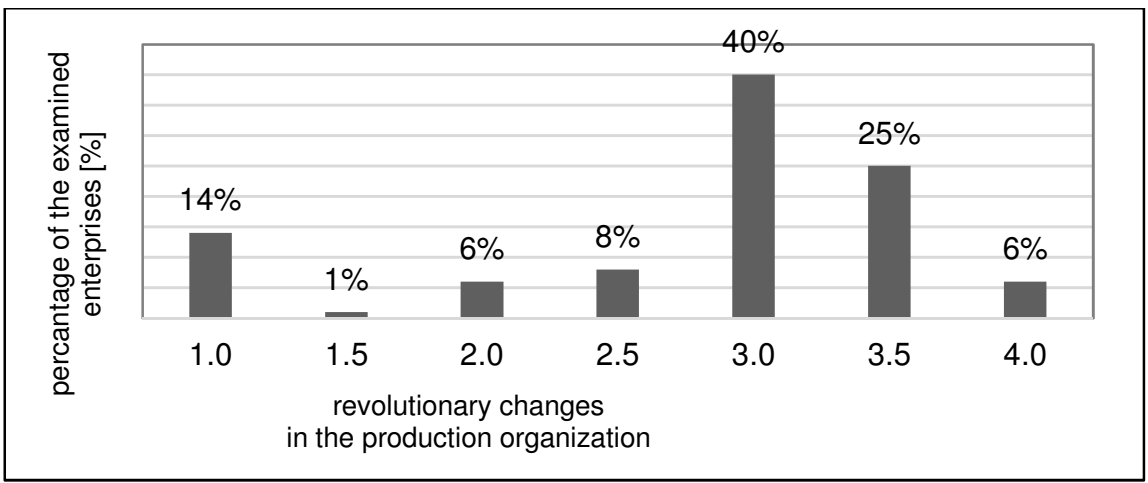

Fig. 2. The industrial revolution level characteristic for Polish enterprises according to Astor Whitepaper in 2016

Figure 3 refers to whether the assumptions that involve Industry 4.0 are part of the corporate strategy.

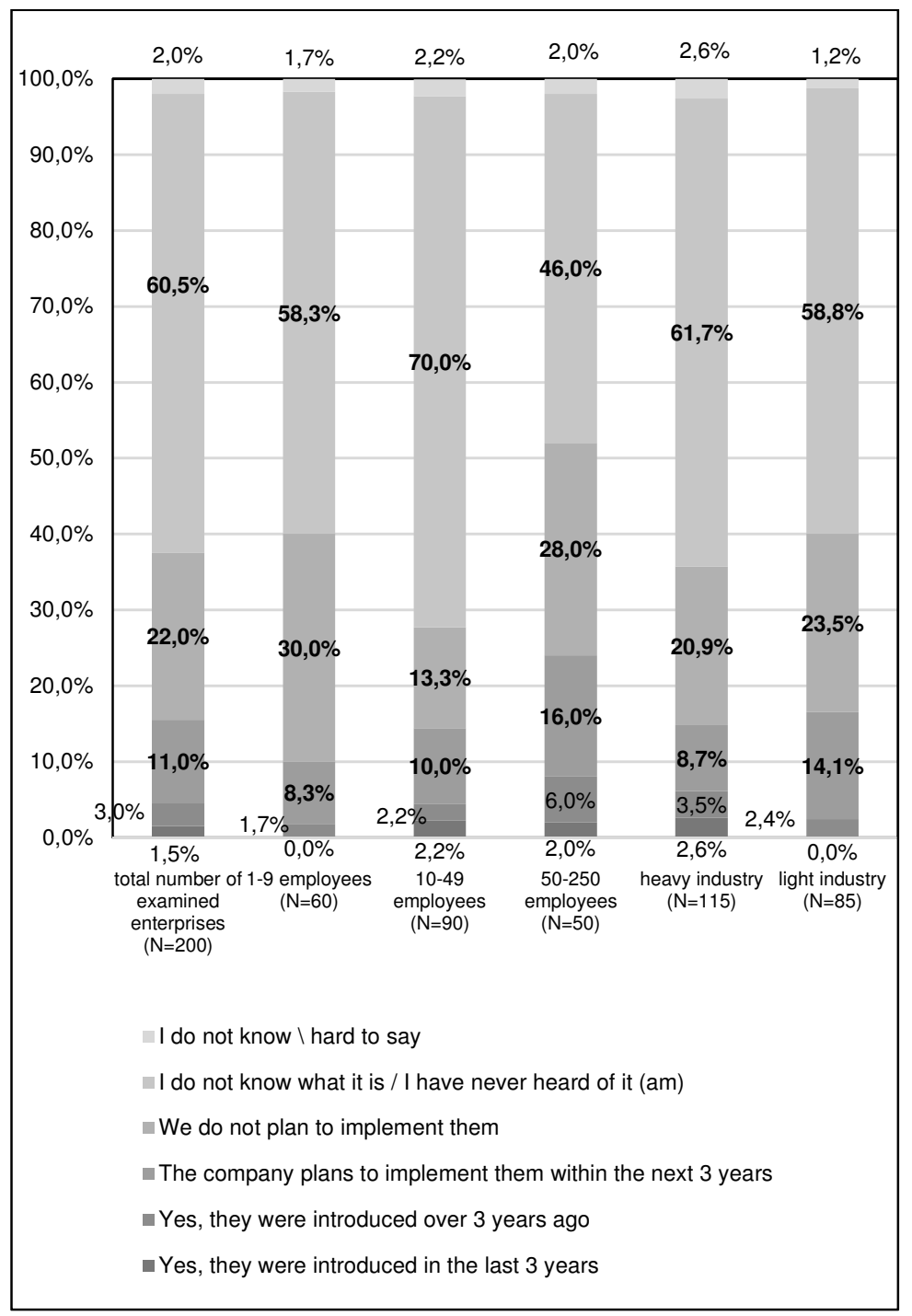

Fig. 3. Are the assumptions of the Industry 4.0 idea an element of your company's strategy?

The process of implementing innovative solutions is combined with several benefits expected by entrepreneurs in the area of production technology. The implementation of each new 
solution in the company aims to improve the competitive enterprise of the market and increase its profitability. Figure 4 presents data on the expected benefits in terms of production technology due implementation of innovative solutions.

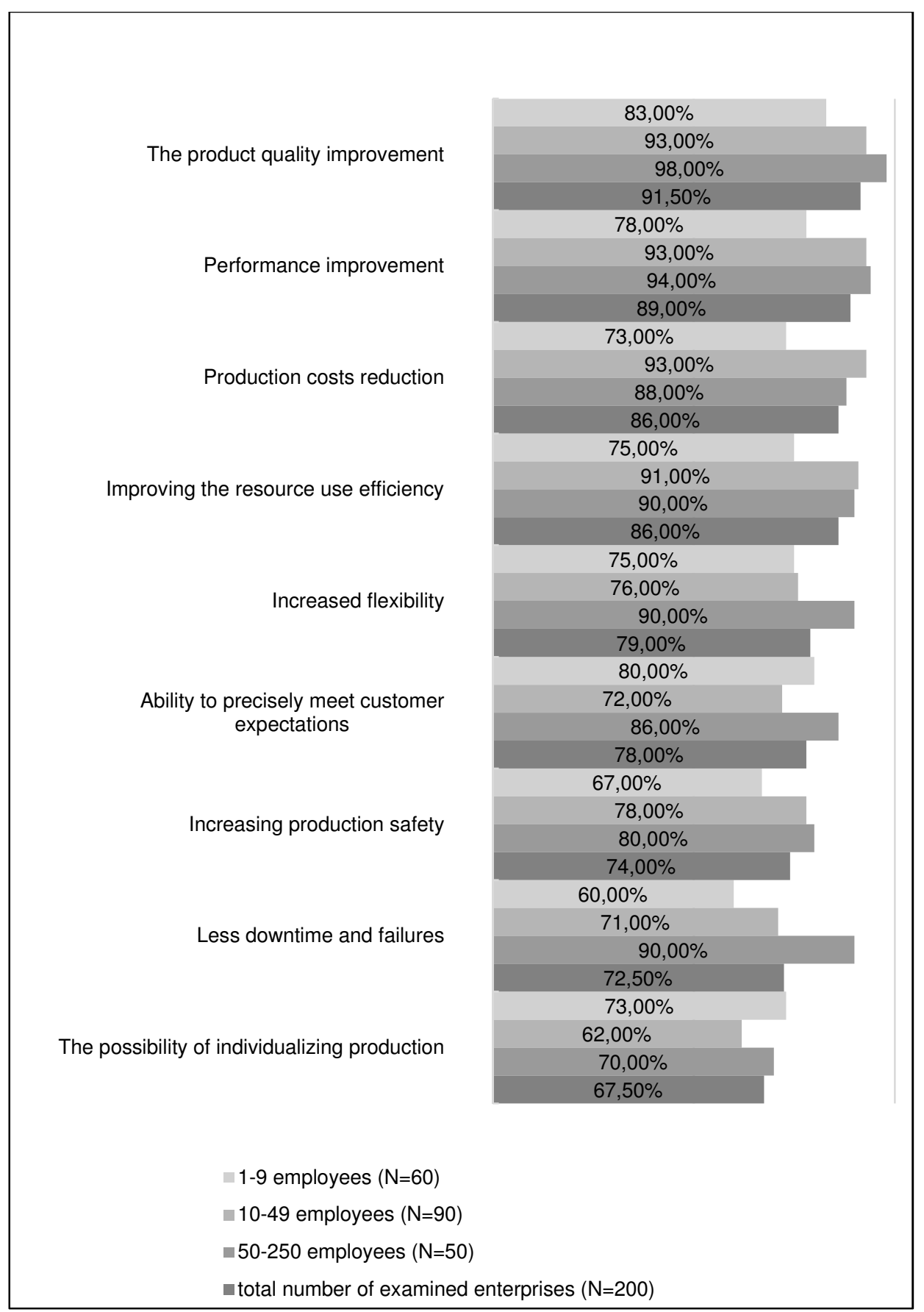

Fig. 4. Expected benefits in the field of production technology in connection with the implementation of innovative solutions

Respondents were asked to identify the biggest barriers to the pace of innovation. One of the biggest barrier is the lack of financial resources for such activities. Figure 5 presents barriers limiting the implementation of Industry 4.0 solutions (innovations) for respondent enterprises. 


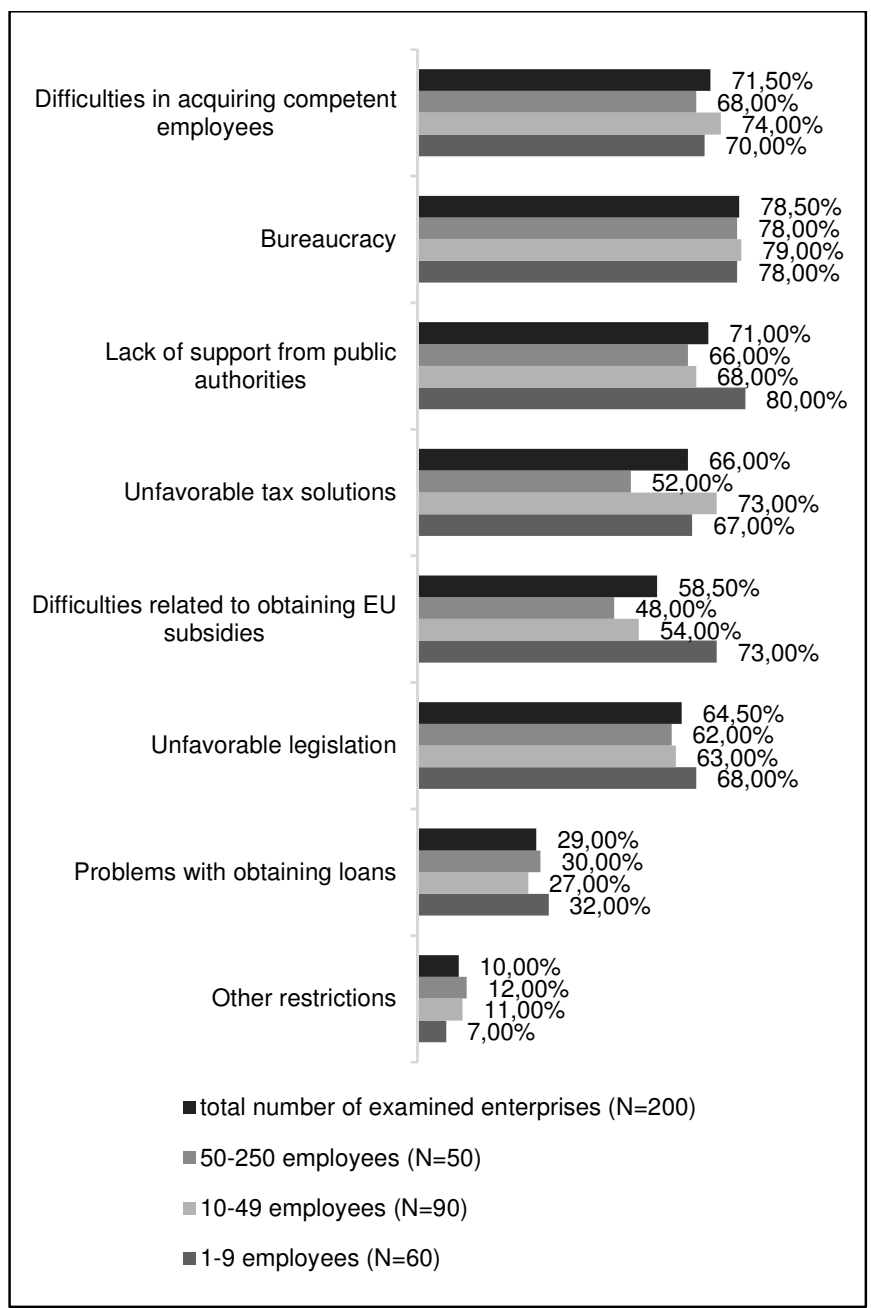

Fig. 5. What external factors limit the implementation of innovation in your company the most?

According to research, most companies are investing in automation of production lines, production and optimization software through which can reduce the cost of prototyping and new product introductions. Figure 6 presents only selected types of technologies used in enterprises implementing solutions of Industry 4.0.

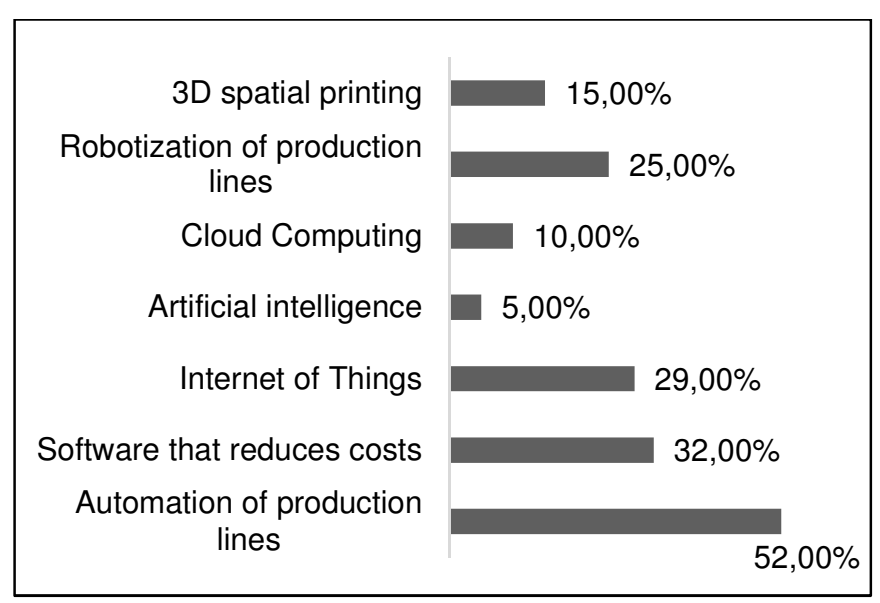

Fig. 6. Selected types of technologies used in enterprises characteristic for Industry 4.0 solutions 
Implementing new solutions is essential to the availability of innovative technological solutions and determine their level of divination in the company. Figure 7 presents degree of difficulty in implementing the technology.

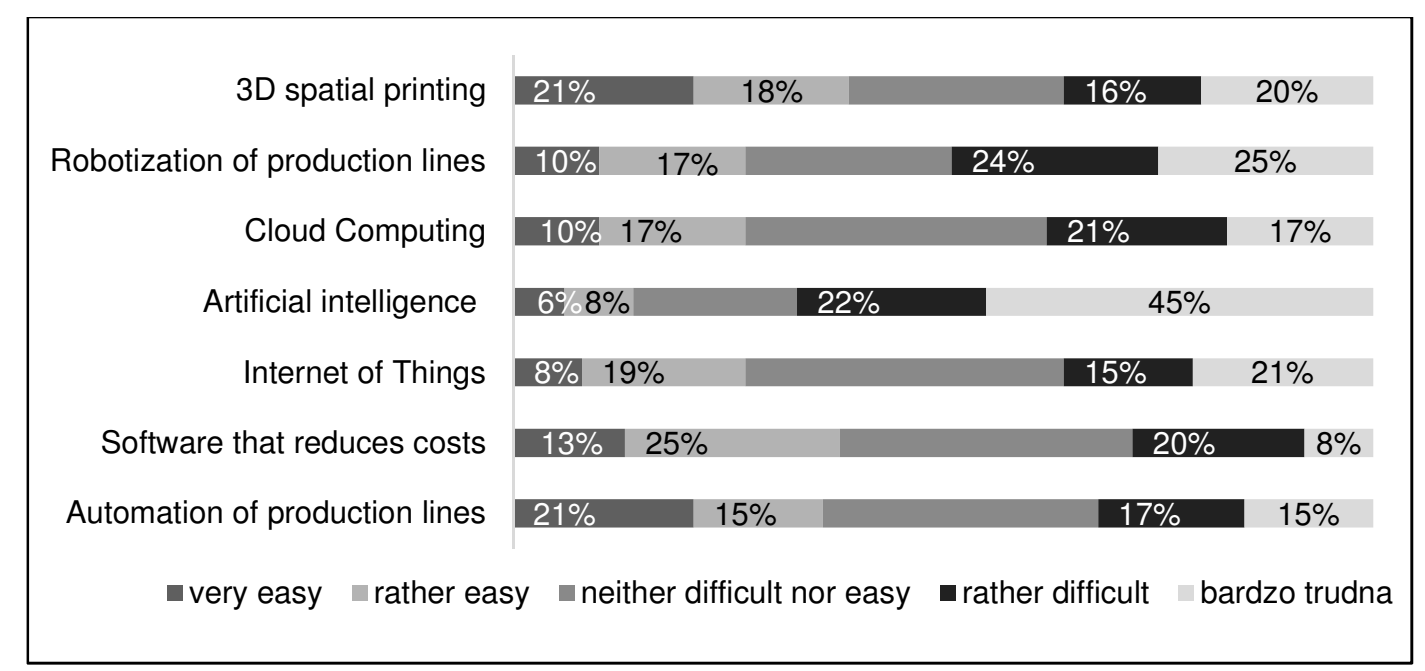

Fig. 7. The degree of difficulty in implementing the technology in the enterprises implementing solutions of Industry 4.0

When introducing new solutions in an enterprise, it is usually expected to improve competitiveness and advantage on the market. Therefore, respondents were asked to indicate the impact of the various technologies that are used by their companies in the construction market position. It can be stated, that the technologies or solutions supporting the innovativeness of the enterprise, of the greatest importance for building a competitive position, are the automation of production lines and data analytics used to optimize production activities. Figure 8 shows the extent to which the implementation of the technology affected the market position.

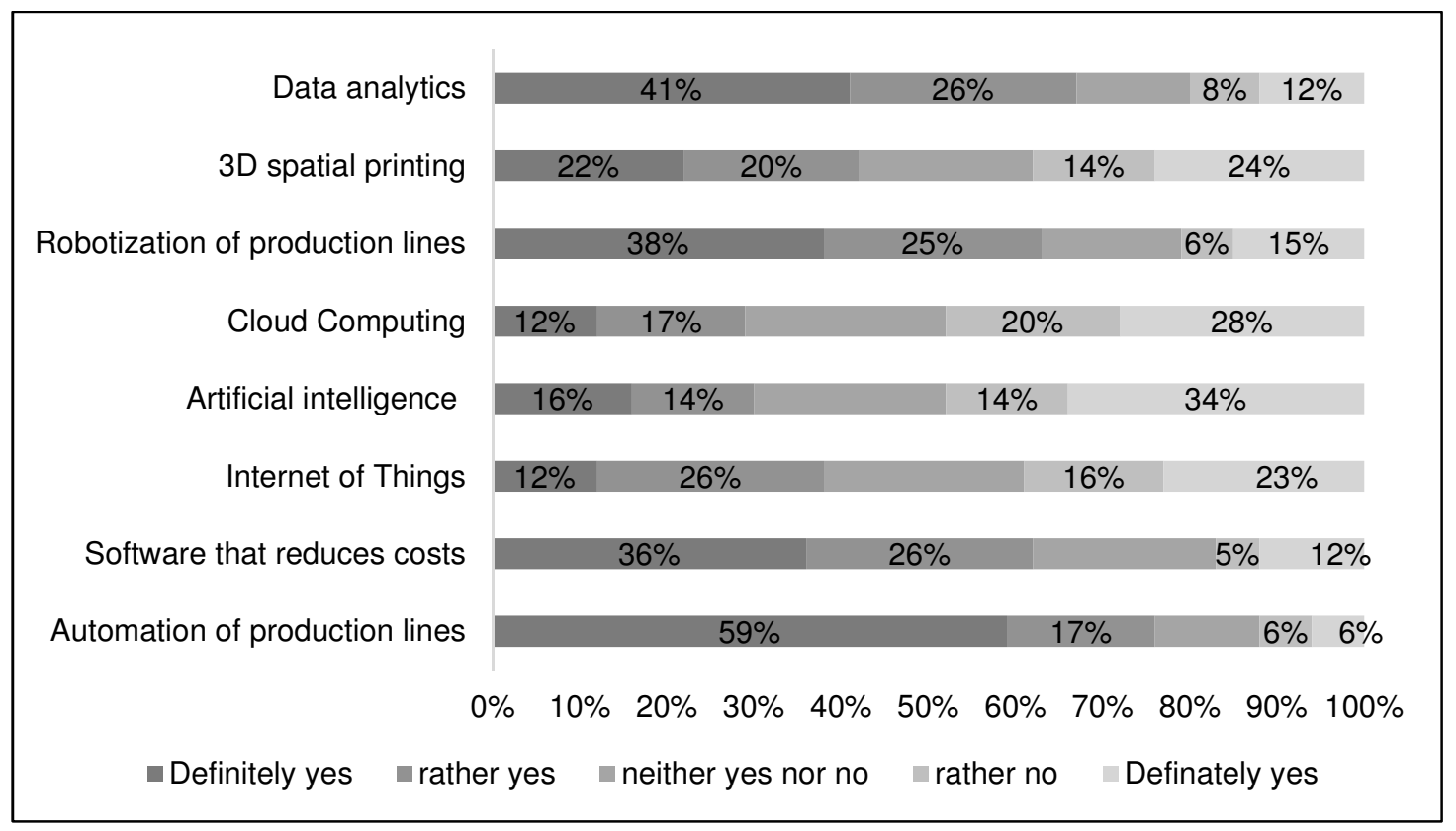

Fig. 8. Degree of influence of technology implementation on the competitive position of the company on the market 


\section{CONCLUSION}

The research results show the image of a Polish entrepreneur trying to keep the enterprise on a competitive market and facing barriers to technological development. It should be noted, that the awareness of enterprises regarding the importance of particular technologies for the development of companies is growing and entrepreneurs want to develop more and more willingly. Thanks to the efficient flow of information, digitally controlled machines will increase productivity, precision and flexibility, automatically exchanging information already in the course of production. This approach will increase the competitiveness of companies that will be responsive to the current needs of the market.

\section{REFERENCES}

Astor Whitepaper in 2016. (2016). Industry 4.0. The revolution is here. What do you know about her? Astor White-paper.

Chen, Y. (2017). Integrated and Intelligent Manufacturing: Perspectives and Enablers. Engineering 3 (2017), pp. 588-595.

Kagermann, H., Lukas, W. and Wahlster, W. (2015). Abschotten ist keine Alternative. In: VDI Nachrichten, Issue 16, (2015).

Kagermann, H., Wahlster, W. and Helbig, J.(2013). National Academy of Science and Engineering. Recommendations for implementing the strategic initiative INDUSTRIE 4.0: Final report of the Industrie 4.0 Working Group. National Academy of Science and Engineering, Munich.

Kusiak, A.(1990). Intelligent manufacturing systems. Old Tappan, NJ: Prentice Hall Press.

Lasi, H., Fettke, P., Kemper, H.G., Feld, T. and Hoffmann, M. (2014). Industry 4.0. Bus Inform Syst Eng, 6 (4) (2014), pp. 239-242.

Lee, J., Bagheri, B. and Kao, H. (2015). A Cyber-Physical Systems architecture for Industry 4.0-based manufacturing systems. Manufacturing Letters, Vol. 3, pp. 18-23.

Lee, X.E. (2015). Made in China 2025: A new era for Chinese manufacturing China CKGSB Knowledge, Beijing. [online] Available at: http://knowledge.ckgsb.edu.cn/2015/09/02/technology/made-inchina-2025-a-new-era-for-chinese-manufacturing/[Accessed on Nov 2 2016].

McFarlane, D., Sarma, S., Chirn, J.L., Wong, C.Y. and Ashton, K. (2003). Auto ID systems and intelligent manufacturing control. Eng Appl Artif Intel, 16 (4) (2003), pp. 365-376.

Plattform Industrie 4.0 (2015). Industrie 4.0 Whitepaper FuE-Themen. Plattform Industrie 4.0, [April 2015].

Revitalize American Manufacturing and Innovation Act of 2014, H.R. 2996, 113th Cong. (2014).

Schmidt M. (2016). 5 emerging technology trends for manufacturers in 2017. Manufacturing News [Internet]. Prospect: Design-2-Part (2016 Dec 15) [cited 2016 Nov 2]. Available at: http://news.d2p.com/2016/12/15/5-emerging-technology-trends-for-manufacturers-in-2017/

Smart Industry Poland (2018), Innovation in the micro sector and small and medium production enterprises in Poland, Research Report, Mini-enterprise of Entrepreneurship and Technology / Siemens, Warsaw.

SMART INDUSTRY POLSKA. (2017). Adaptation of innovations in the activities of micro and small and medium-sized production enterprises in Poland, Raport o badań, Ministerstwo Rozwoju / Siemens Sp. z o.o., Warsaw.

Ulewicz, R. and Nový, F. (2017). Fatigue Resistance and Influence of Cutting Technology on the Mechanical Properties of Modern Steels Used in the Automotive Industry. Procedia Engineering, Volume 192, pp. 899-904.

Ulewicz, R., Jelonek, D. and Mazur, M. (2016). Implementation of Logic Flow in Planning and Production Control. "Management and Production Engineering Review", 7(1), pp. 89-94.

Wang, S., Wan, J., Zhang, D., Li, D. and Zhang, Ch. (2016). Towards smart factory for industry 4.0: a self-organized multi-agent system with big data based feedback and coordination. Computer Networks, Vol. 101, pp. 158-168.

Zhong, R.Y., Xu, X., Klotz, E. and Newman, S.T. (2017). Intelligent Manufacturing in the Context of Industry 4.0: A Review. Engineering, Vol. 3 (5), pp. 616-630. 